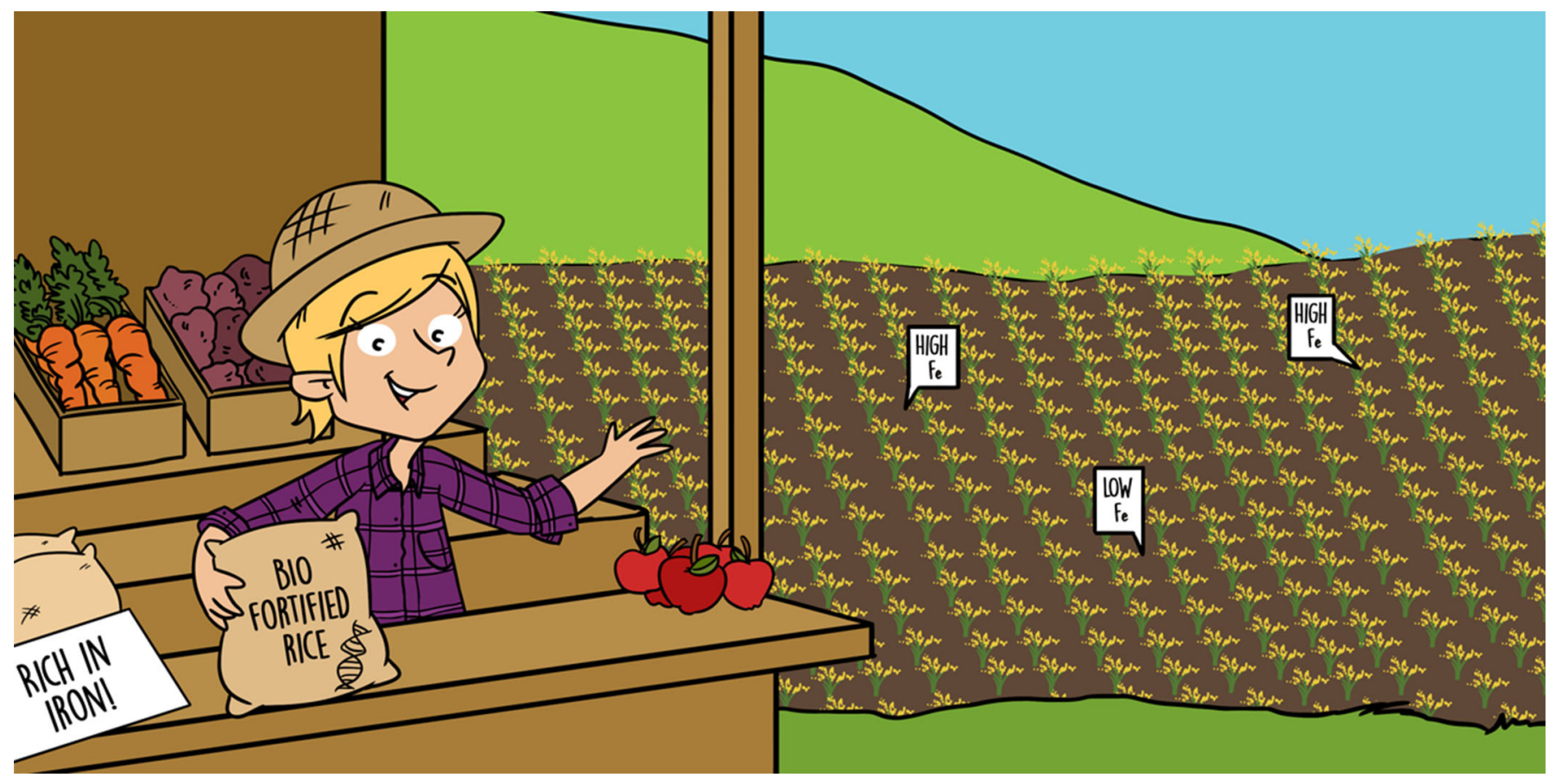

\title{
BIOFORTIFICATION: BATTLING HIDDEN HUNGER
}

\section{Christopher T. DaVeiga, Elizabeth M. Parsons and Jeeyon Jeong *}

Department of Biology, Amherst College, Amherst, MA, United States

YOUNG REVIEWERS:

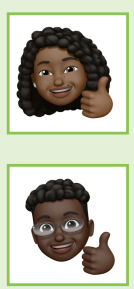

JADA

AGE: 14

JOSHUA

AGE: 14
Around the world, many people suffer from malnutrition. Malnutrition is when the body does not get enough important nutrients to grow or survive and extreme cases can lead to death. Scientists have developed a process called biofortification to improve the nutritional content of crops and prevent malnutrition. Today, biofortification can be done through genetic modification, which involves manipulating the DNA of the crop. One of the most successful examples of a biofortified crop is Golden Rice, a crop enhanced with a substance called beta-carotene, which converts into vitamin A in our bodies. It is important for everyone to learn about biofortification and genetic modification, especially when this process can be used to help many people who would otherwise be suffering from malnutrition.

\section{WHAT IS MALNUTRITION?}

Imagine a disorder that affects 2 billion people worldwide. That is almost one in three people! Sadly, this disorder can cause both mental and physical issues, such as weight loss, decreased heart function, and depression (World Health Organization). But what causes a problem 


\section{HIDDEN HUNGER}

Another term for micronutrient deficiency, meaning a lack of vitamins and minerals needed by the body for proper growth and development.

\section{TRADITIONAL} FORTIFICATION

The deliberate increase of the content of a micronutrient in a particular food.

\section{BIOFORTIFICATION}

A process by which the nutritional worth of food is increased through selective breeding or genetic modification.

\section{SELECTIVE}

\section{BREEDING}

A process by which only certain plants with desired characteristics are allowed to mate and produce offspring to amplify the desired characteristic. that affects so many people? This problem is called malnutrition, and it is related to the food that we eat! Some people suffer from malnutrition because they do not get enough food to eat. But other people who do get enough calories can still suffer from malnutrition, of a different type. When we eat food, it gets broken down inside our bodies, and the various nutrients are removed from the food and separated from each other. Micronutrients are one of the components of the foods we eat. Micronutrients are substances the human body needs in tiny amounts, which is why the prefix "micro" (small) is used. These micronutrients are important for growth, development, and survival. Examples of micronutrients include calcium, potassium, and iron.

When people do not get enough micronutrients, this type of malnutrition is called a micronutrient deficiency. Some people also call micronutrient deficiency "hidden hunger," because a person may feel full but may still not be getting enough micronutrients. The most common hidden hunger is iron deficiency anemia (IDA). IDA occurs when a person does not eat enough iron. Unfortunately, IDA exists in both industrialized and developing countries. IDA is common because it is generally difficult for people to consume enough iron in the form that the body can use. IDA is common in countries with lots of starchy foods, like rice and wheat. These crops provide calories, but few micronutrients. Other types of micronutrient deficiencies include iodine and vitamin B12 deficiency.

\section{WHAT CAN BE DONE TO PREVENT MALNUTRITION?}

In recent years, scientists have searched for solutions to end micronutrient deficiencies. In the past, scientists made foods healthier by adding vitamins to them, which is called traditional fortification. For example, iron can be added to cereal after the grain is processed. These added minerals help lots of people, because cereal is affordable and popular. Another example of traditional fortification is the addition of vitamin $D$ to milk. People can also take supplements, like vitamin pills, to help them get all the micronutrients that they need. However, some people cannot afford or do not have access to supplements or fortified foods. So, scientists have been looking for an alternative solution that will help even more people combat malnutrition caused by micronutrient deficiencies. One of the solutions scientists have come up with is called biofortification. Biofortification is a process that alters crops to improve their nutritional value. Biofortification is different from traditional fortification, because this process changes the plant itself.

\section{HOW IS BIOFORTIFICATION PERFORMED?}

There are two main forms of biofortification (Figure 1). The first is called selective breeding. Selective breeding is when only certain plants with 
Figure 1

An illustration of the different types of fortification. Biofortification focuses on changing the plants before processing either through selective breeding (which involves finding plants with the best traits and breeding them with others that have desirable traits) or genetic modification (further described in Figure 3). Traditional fortification is only involved with food processing, such as adding vitamin $D$ to milk.

\section{GENE}

A unit of heredity that contain instructions for producing proteins.

\section{GENETIC MODIFICATION}

The manipulation of genetic material to alter an organism so as to produce a desired characteristic

\section{NUCLEOTIDE}

The basic structural unit of nucleic acids, such as DNA. The four types are adenine (A), thymine $(T)$, guanine (G), and cytosine (C).

\section{PROTEINS}

Proteins are encoded by genes and serve a variety of roles.

Proteins act to perform a specific function that results in the expression of certain traits in organisms.

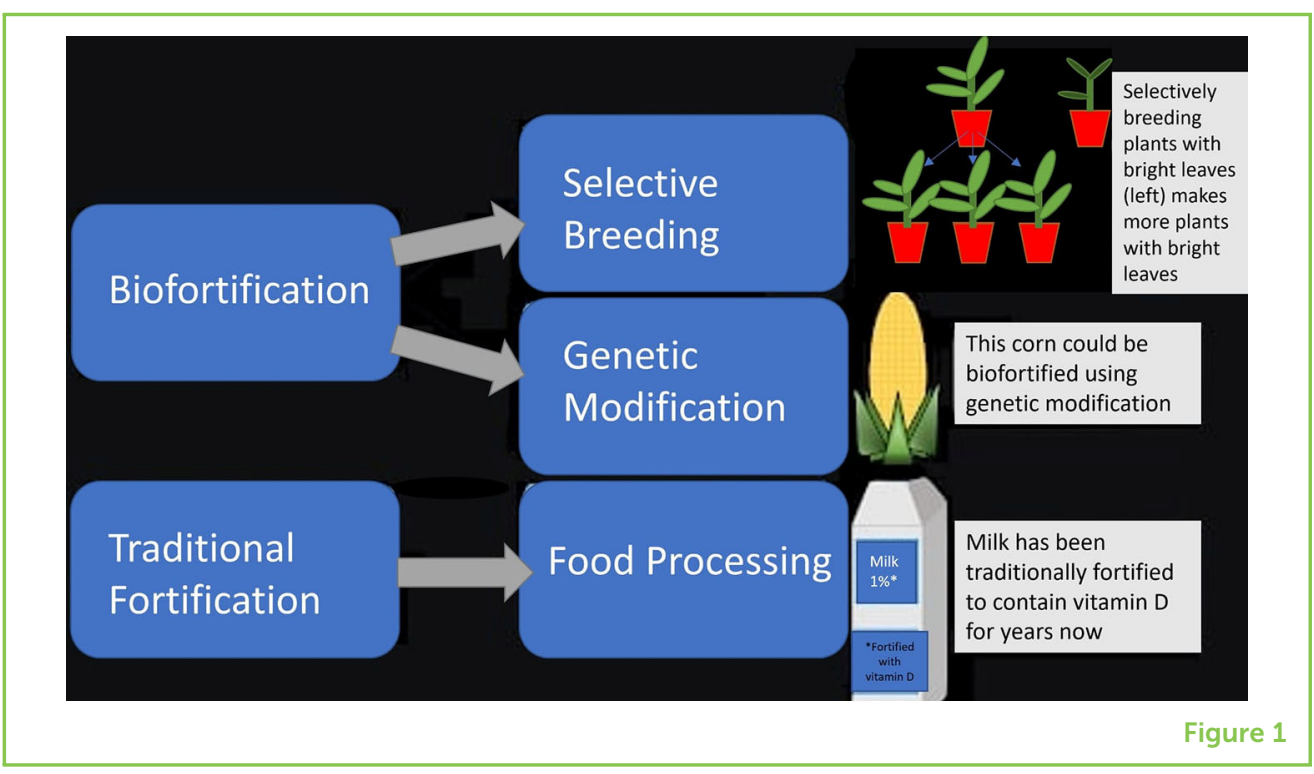

desired characteristics are allowed to grow. For example, picture a patch of land with ten rice plants. Imagine that two of the ten rice plants have naturally higher iron levels. Farmers can remove the eight plants with low iron, and plant seeds only from the high-iron crops for the next season. These seeds would yield more plants with higher iron. When this process is repeated, eventually all the rice plants have higher iron levels than the original ten. Selective breeding uses natural traits to achieve healthier foods.

An advantage of selective breeding is that it is affordable. It does not require any special equipment, so the cost to make a healthier crop is low. However, selective breeding has disadvantages too. For one, selective breeding may hopefully lead to the desired trait, but there is no guarantee because in the process of selecting for the desired trait, other genes will be affected too. That means the plant may develop other unwanted traits. Another issue is that it takes a long time to grow plants, so breeding the best crop can take many years!

A second type of biofortification is called genetic modification. Every living thing has genetic material, which stores instructions for how that organism grows and functions. The main genetic material is deoxyribonucleic acid (DNA). DNA is made of tiny building blocks called nucleotides (Figure 2). Long sequences of nucleotides are called genes, and genes encode for proteins which determine traits. In other words, think of DNA as a recipe book. Each gene is a single recipe within the book. If you look at one gene, it will have a specific order of nucleotide pairs. The nucleotide order is like the steps you find in each recipe. If you read each step carefully, you will make the final product-a protein! Proteins work in cells to do all the important jobs that sustain life. Proteins give living organisms their traits, which are characteristics like your eye color, the height of plants, or the color 
Figure 2

The relationship between DNA, genes, and proteins. DNA is represented at the top of the diagram. The blue and gray lines show the twisting double helix and the rods represent nucleotide bases. Genes are long strands of nucleotides. Think of genes as instructions for building proteins. It is these proteins that determine traits, such as the amount of iron stored in a plant.

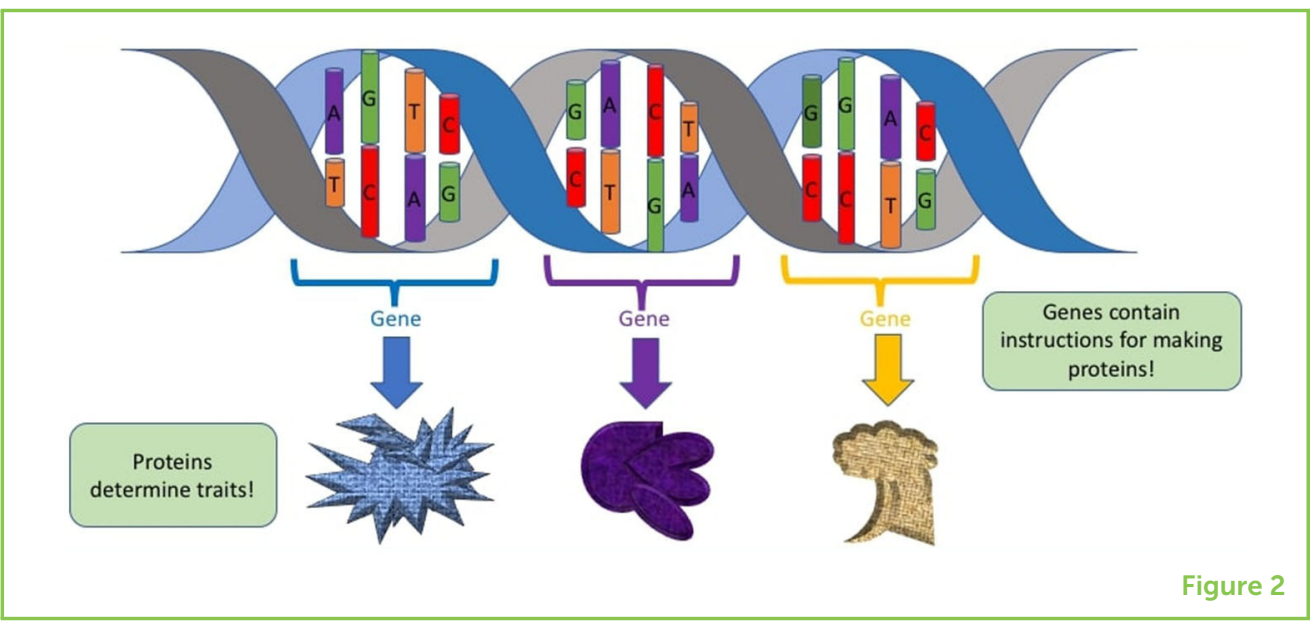

of a peapod. All traits exist because certain genes are present, absent, or expressed (turned on) at different levels.

An advantage of genetic modification is that the desired trait is achieved within a few generations of the plant life cycle after altering the plant. That is much faster than selective breeding. Scientists can directly target the trait they want to change with genetic modification. However, genetic modification also has disadvantages. It requires lots of research and specific biotechnical tools to do, so genetic modification must be done in a laboratory. Also, many people view genetically modified crops in a negative way, so societal acceptance is a major issue.

So, what does all of this have to do with biofortification? Genetic modification changes the genetic code. That means changing the nucleotide order, the genes, and the proteins. Think of the recipe book again, what would happen if you added a new ingredient to a recipe? The color, texture, and flavor might change! This is how scientists can introduce new traits in a plant. Genetic modification is done in two ways. The first is by changing genes that are already in the plant. The second is by inserting new genes into the plant. This method, called gene transfer, is very complex. Genes cannot be easily moved between organisms, so special techniques are used to transfer them. For example, one method uses special pieces of genetic material called plasmids that can be used to "carry" genes and introduces them to the plant. The goal is to modify the genetic code to allow the plant to store more nutrients. These altered foods are called genetically modified organisms, also called GMOs.

To understand how genetic modification works, let us picture the rice farm again. Out of the original ten rice plants, two had the trait of higher iron levels. As we said, a trait is actually just proteins at work! The plants with higher iron levels might have a gene that the low iron-producing plants do not have, or maybe all 10 of the plants have the same gene for high iron levels, but that gene is only expressed 
Figure 3

The creation of Golden Rice. (A) An illustration of the modification performed to make Golden Rice. The beta-carotene biosynthesis gene is taken from the Daffodil flower and inserted into the rice plant. (B) A diagram explaining the impact of the gene insertion. The beta-carotene biosynthesis gene causes the rice plant to produce beta-carotene. The beta-carotene is then turned into vitamin A by a process inside the body.

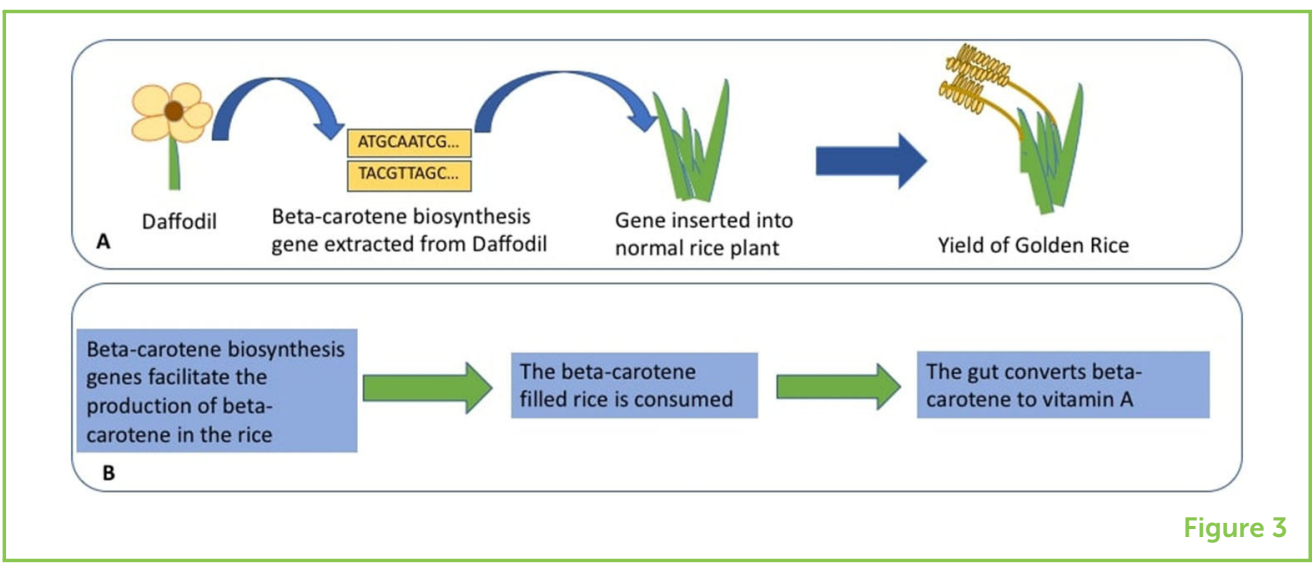

(turned on) in the two plants with high iron. Either way, the offspring of the high-iron rice plants will probably have high iron, too. If scientists wanted to increase the iron levels in the low-iron rice plants, they could use genetic modification to alter the genes in these plants so that the gene for high iron was present or turned on, allowing the plants to accumulate more iron.

\section{GOLDEN RICE}

Golden rice is a real-life example of biofortification. Golden rice is unique because it contains a protein called beta-carotene. Regular white and brown rice do not have beta-cartone. Beta-carotene transforms into vitamin $A$ in the body, and vitamin $A$ is an important micronutrient. A lack of vitamin A can cause blindness and increase the likelihood of contracting measles [1]. Golden rice is made by genetic modification. Scientists inserted two genes from daffodil flowers into the DNA of the rice. These daffodil genes give the rice the ability to produce beta-carotene (Figure 3), which makes the rice healthier because, as we said, beta-carotene becomes vitamin A in the body of the person who eats the rice.

\section{WHY DO WE NEED BIOFORTIFICATION?}

Biofortification genetically alters crops so that they contain more nutrients, and these benefits stay in the crops forever. Many people wonder why biofortification is needed if there are other alternatives, such as traditional fortification and vitamin supplements. There are many benefits to biofortification. It is cost effective, because it does not require the creation of new infrastructure. Also, biofortification is more sustainable than traditional methods of fortification, as biofortified crops require little natural resources after they are generated and can possibly reach more people than can traditional fortification or nutritional supplements. One difficulty with traditional fortification is that every product, such as every batch of cereal or every gallon of 
milk, must be individually altered to add the micronutrients. On the other hand, once a biofortified crop is made, the results last for as long as the crop is allowed to reproduce (which can be forever).

Although there are many benefits to biofortification, it is a controversial topic. Many people worry that it is dangerous to eat biofortified crops. However, many reports by respected organizations, such as the United States National Academies of Sciences have shown that genetically modified foods are safe for people to eat. Overall, it is best for both supporters and critics of GMO foods to remain informed and open-minded.

Biofortification is an important option for decreasing malnutrition. But, helping people to eat balanced diets, providing people with supplements, and performing more research will also aid in battling micronutrient deficiency. Ideally, a combination of these malnutrition-preventing methods would be best. It is vital for scientists to continue to inform the public about biofortification and genetic modification. Accurate information is the only way consumers can make informed decisions about GMOs. Hopefully, with time and improvements in technology, biofortification will become an effective weapon in the battle against malnutrition.

\section{REFERENCES}

1. Enserink M. 2008. Tough lessons from golden rice. Science. 320:468-71. doi: $10.1126 /$ science. 320.5875 .468

SUBMITTED: 12 July 2019; ACCEPTED: 24 July 2020;

PUBLISHED ONLINE: 02 September 2020.

EDITED BY: Jorge Galindo-Villegas, Nord University, Norway

CITATION: DaVeiga CT, Parsons EM and Jeong J (2020) Biofortification: Battling Hidden Hunger. Front. Young Minds 8:114. doi: 10.3389/frym.2020.00114

CONFLICT OF INTEREST: The authors declare that the research was conducted in the absence of any commercial or financial relationships that could be construed as a potential conflict of interest.

COPYRIGHT @ 2020 DaVeiga, Parsons and Jeong. This is an open-access article distributed under the terms of the Creative Commons Attribution License (CC BY). The use, distribution or reproduction in other forums is permitted, provided the original author(s) and the copyright owner(s) are credited and that the original publication in this journal is cited, in accordance with accepted academic practice. No use, distribution or reproduction is permitted which does not comply with these terms. 

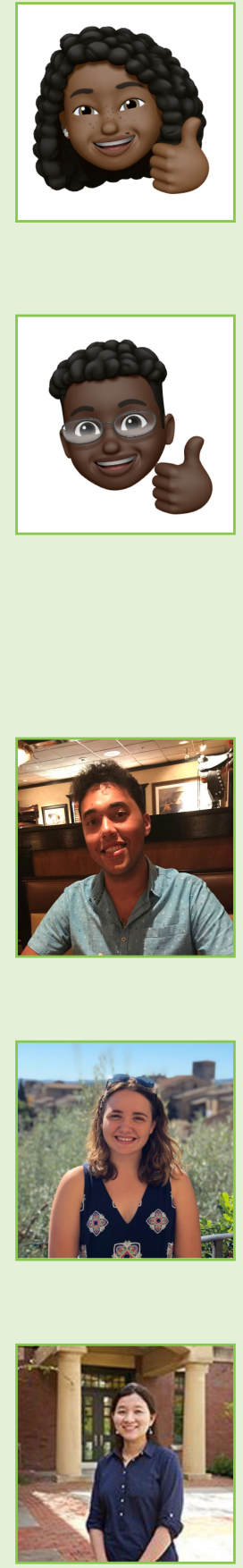

\section{YOUNG REVIEWERS}

\section{JADA, AGE: 14}

Hi! My name is Jada from Atlanta, GA. In my free time, I like to draw/sketch, listen to music, write short stories, and watch an array of movies. I play lacrosse, and I swam for about 5 years. When I become older, I want to be a Cosmetic Plastic Surgeon because I want to make all of my patients proud of their bodies and not insecure about themselves. Helping others is one of my motivations in life!!!

\section{JOSHUA, AGE: 14}

I am a rising ninth grader and I live in Atlanta, Georgia. During the academic school year, I participate in many programs including the Academic team and the Lacrosse team. When I am not studying or at school, I love to read books and play lacrosse. I am happy to be a part of this program because I enjoy science, and I am happy that my feedback is so important in helping people publish their articles.

\section{AUTHORS}

\section{CHRISTOPHER T. DAVEIGA}

Hello! My name is Christopher DaVeiga and I am a senior Biochemistry major at Amherst College. Through my research in the Jeong lab, I have learned a lot about plants and how they incorporate iron. My career goals include going to medical school and becoming a physician. I am originally from Boston, MA, and I spend my free time playing guitar and rooting for the Red Sox.

\section{ELIZABETH M. PARSONS}

Hi! My name is Liz Parsons and I am a Biology major at Amherst College. My research focuses on how plants control the amount of iron in their cells. I have loved science ever since I was little and hope to teach biology in the future. My ultimate goal is to attend medical school and become a doctor. In my free time, I enjoy ultimate frisbee, creative writing, and art history.

\section{JEEYON JEONG}

I am a Biology Professor at Amherst College. I teach Molecular Genetics and Biochemistry, and study genes and proteins that help plants acquire and use iron. Besides research and teaching, I love hanging out with my children and enjoy going to concerts-chamber music and musicals are my favorites. *jjeong (aamherst.edu 